\title{
MANGIARE ALL'ITALIANA: COZINHA REGIONAL, COZINHA NACIONAL OU COZINHA INTERNACIONAL?
}

\author{
Mangiare all'italiana: regional, national \\ or international cuisine?
}

\author{
Paola Baccin* \\ Silvana Azevedo*
}

\begin{abstract}
RESUMO
Há autores que afirmam que não existe uma cozinha italiana, mas um conjunto de cozinhas regionais que, muitas vezes, remetem à tradição dos comuni com suas tradições, seus costumes e até variantes dialetais. O variado cenário histórico, geográfico e cultural não impediu que fosse reconhecida internacionalmente uma "cozinha italiana", cuja importância no mundo gastronômico é indiscutível. A cozinha italiana não é apenas uma somatória das diversas cozinhas regionais, mas tem-se afirmado como identidade ao longo da história, de modo que as práticas alimentares e a cultura gastronômica são elementos essenciais de uma identidade italiana e revelam que os italianos já existiam antes da "existência da Itália". A massa alimentícia é um produto emblemático da história da Itália: é, ao mesmo tempo, alimento requintado e popular. Esse paradoxo acompanha a massa alimentícia em sua viagem ao Brasil. Hoje, a Itália não é mais o país em que a pobreza e a fome expulsam seus habitantes, mas um país que exporta o Italian style e encontra em suas massas alimentícias um símbolo desse estilo. No Brasil, nos dias de hoje, busca-se a autêntica cucina italiana procurando na cozinha de cada região o verdadeiro made in Italy.
\end{abstract}

Palavras-chave: cozinha italiana; massas alimentícias; unificação italiana.

* Universidade de São Paulo (USP). 


\begin{abstract}
Some authors claim that there is no Italian cuisine per se, but a set of regional cuisines that often refer to the tradition of the comuni with their traditions, their customs, and even their dialectal variants. The heterogeneous historical, geographical and cultural background did not prevent an internationally recognized "Italian cuisine", whose importance in the gastronomic world is undeniable. The Italian cuisine is not just a sum of the various regional cuisines. Rather, it has established itself as an identity throughout the history. Feeding practices and food culture are essential elements of the Italian identity and reveal that the Italians had existed before the "Italy as a country". The pasta is a flagship product in the history of Italy: it is at the same time a popular and an exquisite food. This paradox was brought along with the pasta as it came to Brazil. Nowadays, Italy is not the country where poverty and hunger expel its inhabitants, but a country that exports the Italian style and finds in its pasta a symbol of style. In Brazil, when currently seeking for the authentic cucina italiana we actually find the real "made in Italy" in the cuisine of each region.
\end{abstract}

Keywords: Italian cuisine; pasta; Italian unification.

Como um país que chegou tão tarde à unificação (1861-1870) exportou uma identidade culinária? Há autores que afirmam que não existe uma cozinha italiana, mas um conjunto de cozinhas regionais que, muitas vezes, remetem à tradição das cidades: alla bolognese, alla parmigiana, alla napoletana, alla fiorentina.

Pergunte a um italiano sobre a cozinha italiana e, dependendo da pessoa a quem sua pergunta for dirigida, a resposta vai remeter à cozinha bolonhesa, veneziana, romana, milanesa ou toscana, piemontesa, siciliana ou napolitana. Mas, quanto à cozinha italiana, a pergunta soaria como uma daquelas para as quais não existe resposta. A cozinha italiana é na verdade uma cozinha de regiões que precedem no tempo à própria nação italiana, regiões que até 1861 eram parte de estados independentes e muitas vezes hostis, compartilhando poucas tradições culturais, sem uma língua comum [...]. (HAZAN, 1997, p. 4-5).

A tradição e a história italianas reconhecem nos comuni a base da sociedade italiana. Cada comune tem suas tradições, seus costumes e até variantes dialetais e a culinária é uma referência cultural de seus habitantes. Apesar de sua pequena extensão territorial, a Itália apresenta uma diversidade geográfica e climática que permite culturas diversas: ao Norte, 
pecuária, suinocultura, arrozais e milharais; no Centro-sul, oliveiras e trigo duro. Os diferentes preparos resultam dos ingredientes produzidos naquelas regiões e das várias influências de povos estrangeiros que, ao longo da história, invadiram a península. Esse cenário - histórico, geográfico e cultural - tão variado não impediu que fosse reconhecida internacionalmente uma "cozinha italiana", cuja importância no mundo gastronômico é indiscutível.

A cozinha italiana não é apenas uma somatória das diversas cozinhas regionais, mas tem-se afirmado como identidade no caminhar da história. Ao restituir à arte da gastronomia sua dimensão própria, independente de outros fatores que lhe são externos, conclui-se que as práticas alimentares e a cultura gastronômica são elementos essenciais de uma identidade italiana e revelam que os italianos já existiam antes da "existência da Itália".

A tradição gastronômica e alimentar caracteriza-se não pela sua inserção em determinado território, mas pelos traços opositores que a distinguem de outras. $O$ produto local adquire uma identidade geográfica quando é deslocado e inserido em outra cultura. o primeiro deslocamento ocorre da área de produção ao centro de comercialização, em geral localizado nas cidades. O segundo deslocamento ocorre da área de comercialização para outras regiões ou outros países. Capatti e Montanari (1999) citam, como exemplo, a mortadela de Bolonha como um produto que assume essa denominação apenas no momento em que sai do seu ambiente de produção no momento do intercâmbio com outras regiões e culturas. A exportação e fixação de um ingrediente, de um modo de preparo, de uma receita e sua respectiva terminologia em um novo país iniciam o processo natural de adaptação e consequente contaminação, gerando um novo produto. A terminologia pode adaptar-se ao novo produto ou pode manter-se cristalizado, assumindo apenas uma nova acepção na nova língua, criando uma variante.

Tudo é classificado e identificado pela sua inserção em um conjunto e natural oposição a outros. Os pares reconhecem-se como pertencentes a um mesmo conjunto, segundo um determinado nível de classificação e identificam-se pela oposição aos não pares, que pertencem a outro conjunto nesse mesmo nível. Em um nível de classificação mais alto, esses dois conjuntos podem se reconhecer como um único conjunto, em oposição a outro. o imigrante é identificado pelos brasileiros como o italiano (em termos de país); será reconhecido, porém, como napolitano, trevisano, ou triestino (em termos de cidade) pelos outros italianos. Como as pessoas, as receitas e os ingredientes são classificados e recebem uma denominação em níveis diversos.

A culinária, portanto, se revela não tanto pela sua origem, mas como lugar de intercâmbio e de contaminação por excelência. Se um produto pode ser expressão de um território, seu uso em uma receita ou em um cardápio é quase sempre fruto de hibridação. (CAPATTI; MONTANARI, 1999, p. 9). 


\section{LA PASTA: O MACARRÃO COMO INGREDIENTE FUNDAMENTAL DA COZINHA ITALIANA}

Aceitando-se o intercâmbio e o consequente estabelecimento de características opositivas em graus diversos como principais fatores para a identificação de uma cozinha tipicamente italiana, passamos a considerar o comércio como um exportador do território cujos produtos exportados passam a ser reconhecidos pelo seu centro de mercado, localizado nas cidades (primeiro deslocamento) ou pelo seu país de origem (segundo deslocamento). Os produtos que obtêm uma maior circulação no mercado externo são aqueles que podem ser conservados por um período mais longo. (CAPATTI; MONTANARI, 1999, p. 11).

As massas alimentícias, que abrangem as massas secas e as massas frescas com toda a sua tipologia de formatos, são elaboradas, basicamente, com dois ingredientes, farinha de trigo e água; podem ser conservadas por um longo período e podem ser combinadas com os mais diversos ingredientes.

Há muitas histórias sobre a origem das massas alimentícias. A mais conhecida - e hoje já desacreditada - conta que, ao voltar de uma viagem da China, em 1295, Marco Polo teria mencionado, entre as muitas maravilhas daquele país, "mangiari di pasta assai e buoni", ou seja, diversas massas deliciosas feitas com farinha de arroz ou farinha de soja (BONI, 1827, p. 165). Mariaelena Mondelli (2001) observa que Marco Polo deveria ter acrescentado, para evitar falsas interpretações, que "tais massas eram tão boas quanto as que ele havia, tantas vezes, comido na Itália".

Conhecida desde os tempos dos romanos, não se sabe, com certeza, quando a produção da massa alimentícia passou a representar o negócio lucrativo de hoje. Podemos supor que a extraordinária capacidade de conservação da massa propiciou o seu transporte e, portanto, a sua inserção em várias regiões da península itálica e da Europa. (CAPATTI; MONTANARI, 1999, p. 64).

Muitas cidades reivindicam a paternidade da massa alimentícia. Palermo (Sicilia), Nápoles (Campânia) Gênova (Ligúria) são consideradas le capitali della pasta, ou seja, as capitais da massa alimentícia.

Em 1604, Ortensio Lando atribui a Meluzza Comasca (de Como) a invenção do macarrão no Catalogo degli inventori delle cose che si mangiano.

Em 1773, Jacopo Vittorelli escreve o poema jocoso I maccheroni, em que atribui a invenção do macarrão a Pulcinella, um dos personagens típicos da Comedia dell'Arte. (VITTORELLI, 1809, p. 110-118).

O conde Francesco de Lemene (1634-1704) publica, em Modena, o poema Della discendenza e nobiltà de maccaroni (MONDELLI, 2001, p. 20), em que ironiza as contendas entre algumas cidades que disputavam a invenção das massas alimentícias: 
[...] sono Napoli e Bergamo nemici [...] Facendo gran contesa e gran fracasso più per $i$ Maccheroni che per il Tasso.

[...] são Nápoles e Bergamo inimigas [...]. Armam mais controvérsias e balbúrdias pelo Macarrão do que por Tasso (o poeta).

O poema é um dos primeiros documentos da existência de duas máquinas essenciais para a fabricação de massas em escala industrial: a gramola (instrumento para sovar a massa) e o torchio (prensa); e descreve, também, as formas que assumiram as massas ao longo da história:

De Farinha nasceu Massa: mãe prolífica que, viúva, teve um filho natural chamado Nhoque [...]. De seus três maridos - Cannella (pau de macarrão), Gramola e Torchio - tivera outros filhos. Com Cannella gerara Polenta e Lasanha, esta, máe de Torta e de Raviole. Mas foi com Torchio que Massa gerou a flor de sua estirpe, Maccarone, do qual descende Fidelino, pai de Pestarino. ${ }^{1}$

A presença de imigrantes italianos em todos os continentes favoreceu a popularização das massas alimentícias pelo mundo. A frugalidade de seus ingredientes básicos, a facilidade de transporte e de exportação, seu valor nutricional e a sua capacidade de adaptação aos diferentes gostos locais, aceitando como condimento ingredientes variados, são alguns dos fatores da grande popularização das massas alimentícias em todo o mundo.

Giuseppe Prezzolini (apud DEIANA, 2011, p. 21), ao constatar que muitos americanos não conheciam Dante Alighieri, declara: che cosè la gloria di Dante, appresso a quella degli spaghetti? Capatti e Montanari (1999, p. 16) não se surpreendem com essa constatação e afirmam que apesar de ser uma arte iletrada, a cozinha sobrevive pela tradição oral e tem, por esse motivo, um papel civilizador, concluindo: in fondo negli spaghetti, senza esserne coscienti, si mastica qualcosa di Dante.

\section{As MASSAS ALIMENTÍCIAS: INFORMAÇÕES HISTÓRICAS}

$\mathrm{Na}$ Roma assolada por uma gravíssima carestia, em 490 a.C., o Senado decreta o primeiro tabelamento de preços (calmiere) e adquire uma grande quantidade de trigo para ser distribuído ao povo gratuitamente

\footnotetext{
${ }^{1}$ Tradução livre do trecho publicado em GRIGUOL, 2001, p. 34-35.
} 
ou por uma quantia irrelevante. Para a conservação, além do sistema de tostadura (tostatura), os romanos utilizavam, para a farinha de trigo duro (grano duro), o sistema de cozimento na água; a pasta, assim obtida (os chamados pastilli), poderia ser conservada, trabalhada e submetida ao processo de secagem.

A primeira indicação da existência de algo parecido com a massa remonta à civilização grega, no primeiro milênio antes de Cristo. A palavra grega laganon era usada para indicar uma grande folha achatada de massa, cortada em tiras. (BARILLA, 2001, p. 11).

Em 35 a.C, Horácio Flacco descreve sua refeição frugal composta de legumes e lagane: "finas tiras de farinha e água, cozidas em um caldo com gordura, temperadas com queijo, pimenta, açafrão e canela" (MONDELLI, 2001, p. 197). Essa origem é contestada em a Grande enciclopedia illustrata della gastronomia ${ }^{2}$ (2000, p. 491, 630), em que se afirma que o laganon ou laganum, comum às culturas gregas e romanas, deveria ser uma espécie de focaccia (tipo de pão) ao forno e não o que nós conhecemos como lasanha. GEI (2000, p. 491) informa que o registro da palavra em um poema do Frei Jacopone da Todi, do fim do século XIII - "Chi guarda a maggioranza spesse volte si inganna. Granel di pepe vince per virtù la lasagna" - poderia referir-se a um tipo de nhoques grandes.

No século I a.C., Marco Terenzio Varrone no De lingua latina refere-se a lixulae, que são uma espécie de nhoques feitos com água, farinha e queijo, considerados um dos alimentos mais pobres da época (MONDELLI, 2001, p. 196). As massas alimentícias eram um remédio nas emergências, uma resposta das camadas mais pobres às crises e à fome sempre presentes. Muitos escritores latinos da época citam em suas obras produtos e especialidades gastronômicas da península. Segundo Capatti e Montanari (1999, p. 3-4), a geografia subjacente a tais referências não é a Itália, mas sim, de um lado, o sonho arcádico da autarquia familiar, em que a horta fornece o alimento honesto e frugal, e, de outro, o da Roma caput mundi, o grande mercado universal, onde se pode encontrar e comprar todos os recursos: naturais ou inventados pelo homem. A primeira evocação representa Roma em busca de suas próprias raízes e refere-se a uma gastronomia local, aberta aos territórios itálicos. A segunda representa o desejo de globalização, ou seja, ver o Mediterrâneo transformado em mare nostrum. O império não anula as identidades culturais e territoriais, absorve-as. Concluem os autores: "Roma nunca se identificou com o país que a viu nascer e preferiu o império à Itália." (CAPATTI; MONTANARI, 1999, p. 4).

${ }^{2}$ Doravante: GEI. 
No quarto livro de Apício, De re coquinaria, (apud GRIGUOL, 2001, p. 31), reencontramos as lagane, transformadas em um sofisticado prato composto por camadas de carne e de peixe cozidos e desfiados, ricamente temperados, e por camadas de folhas de massa alimentícia. O texto de Apício explica, em detalhes, a preparação dos recheios e dos molhos, mas não explica como confeccionar as lagane. Pressupõe-se que, na época, o preparo da massa já fosse de conhecimento geral.

Capatti e Montanari (1999, p. 59-60) informam que as primeiras massas secas foram produzidas pelos árabes do deserto com a intenção de conservá-las durante suas peregrinações. Surgem, assim, pequenos cilindros de massa cujo furo central permitia uma secagem rápida. Segundo os autores, o documento mais antigo sobre essa técnica, em que encontramos o registro de diversos formatos de massas secas, é o livro de culinária de Ibran' al Mibrad (século IX). Entre as receitas, está registrada a rista, um prato muito comum entre as tribos dos beduínos e ainda hoje conhecido na Síria e no Líbano, preparado com massa seca e que podia ser temperado de diversas formas. É, portanto, atribuída aos árabes a paternidade das massas secas de longa conservação, ou seja, a transformação de um produto manufaturado em produto industrial, propício ao transporte e à comercialização.

Os árabes teriam levado essas técnicas à Sicília, durante a ocupação da Ilha, entre os séculos IX e XI. Na Itália, os primeiros documentos históricos de produção de massa seca artesanal-industrial remetem à Sicília do século XI. Por essa razão, Palermo é considerada, historicamente, a primeira verdadeira capital da massa na Itália (GRIGUOL, 2001, p. 11). Gênova, outra capital da massa alimentícia, por volta do ano 1000, mantinha o monopólio do comércio de trigo no Mediterrâneo (GEI, p. 521); já Nápoles, até o século XIV, importava massas alimentícias da Sicília.

No século XII, durante o domínio normando, a Sicília produz e exporta massa seca para outras regiões meridionais. Por volta do ano 1154, o geógrafo árabe Al-Idrisi conta que em Trabia, a trinta quilômetros de Palermo, "fabrica-se tanta massa alimentícia em forma de fios, chamada 'triyan' (do árabe, 'itrija'), que é exportada para muitas localidades, desde a Calábria até tantos paises muçulmanos e cristãos inclusive por via marítima" (MONDELLI, 2001, p. 197). Segundo a Grande enciclopedia illustrata della gastronomia (GEI, p. 520), tanto a "pista" genovesa quanto a "pista" siciliana conduzem a uma origem oriental, provavelmente mongólica, do macarrão (como massa seca). Trazido pelos árabes à península itálica, o produto teria sido desenvolvido por italianos e chineses, cada um à sua maneira.

No século XII, os mercadores genoveses já eram os principais difusores da massa alimentícia siciliana nas regiões do Norte. Em pouco tempo, a Ligúria se estabelece como a principal área de produção e de comércio de 
vermicelli e de outros tipos de massa. Alguns livros de culinária da época apresentam receitas de tria como tipicamente genovesas. ${ }^{3}$ Essa informação aparece novamente em publicações posteriores até o fim da Idade Moderna.

Documentos notariais do Arquivo de Estado de Gênova atestam a produção de massa seca na Ligúria entre 1200 e 1300. Em 2 de agosto de 1244 , o médico de Bergamo, Ruggero di Bruca, em ato registrado pelo tabelião Giannino di Bredono, assume o compromisso de curar Bosso, operário de um lanifício, de uma doença na cavidade bucal, em troca de sete liras genovesas. O doente, diante de testemunhas, compromete-se em não consumir alguns alimentos, entre os quais a massa cozida (pasta lissa). ${ }^{4} \mathrm{Em} 4$ de fevereiro de 1279 , o tabelião Ugolino Scarpa redige um documento em que atesta que o soldado Ponzio Bastone deixa como herança, entre coisas de pouco valor, também uma bariscella plena de macaronis. Segundo Mondelli, para ser deixada como herança, trata-se, é certo, de massa seca, provavelmente em forma de pequenos nhoques como os atuais nhoques sardos (gnocchetti sardi). Este é o primeiro registro da palavra maccherone. (GEI, p. 520)

Ao mesmo tempo, há documentos que registram o consumo de massas frescas como lasagne, tortelli e uma pasta di granelli $i^{5}$ nas refeições festivas determinadas segundo um calendário definido pelos eremitas de Camaldoli, na região dos Apeninos entre a Toscana e a Emília (CAPATTI; MONTANARI, 1999, p. 61).

A partir do século XIII, a massa italiana é conhecida também fora da península. Segundo o poeta Walter von der Vogelweide, Frederico II amava, principalmente, i maccheroni dal sugo dolce, massas com molho adocicado, preparadas com açúcar, como era habitual na época. Nesse período, aumentam os registros de massas frescas em documentos históricos, literários e religiosos.

Frei Salimbene da Parma (1221-1282) conta, em sua Crônica, de um frei grande e corpulento, um tal de Giovanni da Ravenna: "non vidi mai nessuno che come lui si abbuffasse tanto volentieri di lasagne con formaggio" ("nunca conheci alguém que se empanturrasse, com tanto gosto, de lasanhas ${ }^{6}$ com queijo", tradução nossa) (GRIGUOL, 2001, p. 32).

${ }^{3}$ Liber de coquina, II, p. 62, apud CAPATTI; MONTANARI, 1999, p. 60-61.
${ }^{4}$ MONDELLI, 2001, p. 198; BARILLA, 2001, p. 13; GEI, p. 521.
${ }^{5}$ Uma massa de grãos, provavelmente um tipo de massa pequena e redonda chamada millefanti (CAPATTI; MONTANARI, 1999, p. 66). Mariaelena Mondelli registra que, em 1570, Bartolomeo Scappi descreve um tipo de massa seca ao sol e conservada em saquinhos, denominada Mille fanti, no formato de pequenos grãos de milho, resultado de uma mistura de farinha e água morna: "Tra le varie ricette sulla pasta da segnalare $i$ Mille fanti, ottenuti da un impasto di farina e acqua tiepida rivoltato fino ad 'ottenere tanti granelli grandi come miglio, che, fatti seccare al sole, si conservano in sacchetti”' (MONDELLI, 2001, p. 199).

${ }^{6}$ Optamos pela forma plural uma vez que se trata, aqui, de um prato feito com tiras de massa chamadas lasanhas. O nome no singular, usado em português, refere-se ao prato conhecido no Brasil, fruto de uma adaptação linguística. 
Cecco Angiolieri admoesta: "chi de l'altrui farina fa lasagne, il su' castello non ha ne muro ne fosso" ("quem faz lasanhas com a farinha alheia, terá um castelo sem muro e sem fosso", tradução nossa) (GRIGUOL, 2001, p. 32).

O primeiro livro da literatura gastronômica italiana foi o Liber de coquina. Escrito em latim, provavelmente na corte de Anjou, reino de Nápoles, documenta uma cozinha destinada aos nobres. É a expressão de uma cultura sincrética, fruto de uma visão internacional, europeia e árabe. Conhecido também na França e na Alemanha, foi utilizado do século XIII até o final do século XV. Exemplos de receitas revelam que havia na época um intercâmbio de informações gastronômicas. São citados, entre outros pratos, couves à romana, folhas à moda da Campânia, feijões à moda de Treviso. ${ }^{7}$ Segundo os autores, algumas denominações têm um caráter encomiástico ocasional, como por exemplo, a torta lavagnese, que, é provável, não seja uma receita típica da Ligúria, mas uma homenagem a Sinibaldo Fieschi, dos Condes de Lavagna, eleito Papa Inocêncio IV, em junho de 1245. A cozinha italiana da época afirma-se como um lugar de intercâmbio entre realidades diversas cujas informações culturais circulam dentro do território. As principais regiões de irradiação dessa cultura são o reino de Nápoles (corte de Anjou) e a Toscana dos comuni.

A primeira parte do Liber de coquina é dedicada às verduras que, na época medieval, não eram o alimento principal à mesa dos poderosos, ${ }^{8}$ os quais preferiam as carnes. Essa preferência é fruto do contato com os povos germânicos cujos costumes alimentares estavam intimamente ligados à caça $\mathrm{e}$ à criação de rebanhos. A cultura romana, inspirada no modelo grego, identificava no trigo, na uva e nas oliveiras os símbolos de uma civilização agrícola e citadina. As populações germânicas, que invadiram o império e afirmaram-se politicamente, propiciaram o surgimento de uma nova cultura gastronômica, hoje reconhecida como europeia, em que o pão e a carne são dois componentes de um mesmo sistema de valores. Aos poucos, a cultura árabe, que proibia a carne de porco e o vinho, passa a ser considerada estranha à Europa. Para compreender esse panorama, é necessário distinguir a cultura gastronômica dos nobres e poderosos dos costumes da população mais pobre, e o intercâmbio entre as duas classes sociais. O Liber de coquina cita, por exemplo, as fave infrante, uma espécie de polenta de favas, típica da alimentação dos agricultores,

7 “[...] cavoli ad usum Romanorum, delle 'foglie minute' (ancora, probabilmente, cavoli) ad usum Campanie, dei fagioli 'all'uso della Marca di Treviso'; e ancora, una simula pugliese, una tria genovese, una torta parmesana [...] e un compositum lonbardicum ovvero la mostarda che oggi chiamiamo di Cremona." (CAPATTI; MONTANARI, 1999, p. 9).

${ }^{8}$ CAPATTI; MONTANARI, 1999, p. 41-43. 
conhecida também pelo nome de macco, que, segundo alguns estudiosos, é a origem da palavra maccherone (CAPATTI; MONTANARI, 1999, p. 53) A inventividade da camada mais pobre da sociedade nos momentos de necessidade gera criações culinárias originais que são incorporadas pelos nobres.

Em relação às massas alimentícias, o Liber de coquina explica, com detalhes, como fazer e cozinhar as lasanhas. O livro cita, ainda, entre outros formatos de massas alimentícias, os croseti, ${ }^{9}$ a ancia alexandrina ${ }^{10} \mathrm{e}$ a tria ianuensi ou massa genovesa. o condimento para a massa é o queijo, que pode ser ralado ou cortado em fatias (gratatum ou incisum) (CAPATTI; MONTANARI, 1999, p. 61-63).

O primeiro registro na língua literária da palavra macarrão (dei maccheroni) como massa alimentícia na forma de nhoques está no Decamerão (1348-1353), de Giovanni Boccaccio (1313 (?)-1375) na célebre descrição do país de Bengodi:

Maso rispose che le più si trovavano in Berlinzone, terra de'Baschi, in una contrada che si chiamava Bengodi, nella quale si legano le vigne con le salsicce, e avevasi un'oca a denaio e un papero giunta, ed eravi una montagna tutta di formaggio parmigiano grattugiato, sopra la quale stavan genti che niuna altra cosa facevan che far maccheroni e raviuoli, e cuocergli in brodo di capponi, e poi gli gittavan quindi giù, e chi più ne pigliava più se n'aveva; e ivi presso correva un fiumicel di vernaccia, della migliore che mai si bevve, senza avervi entro gocciol d'acqua. (Giornata VIII, novella 3, p. 22).

Há muitos outros documentos literários do século XIV ${ }^{11}$ nos quais são citados exemplos de massas alimentícias:

le zuppe lombarde, le lasagne maritate, le frittelle sambucate em Rime de Franco Sacchetti;

donne che vendono uova con formaggio / per far degli erbolati e delle torte / e raviuoli ad altro di paraggio, de Antonio Pucci (1309-1388).

É desse século a difusão das expressões essere di buona pasta, ser uma pessoa de boa estirpe, ou ainda, ser uma pessoa boa e amável e seu antônimo, essere di pasta grossa.

\footnotetext{
${ }^{9}$ Trata-se dos corzetti genoveses e provençais, similares aos cavatelli da Puglia. Tipo de nhoques redondos e alongados, com uma cavidade central feita pressionando-se um dedo no centro da massa.

${ }^{10}$ Feita com semola apula e cozida em leite de amêndoas; ancia teria o significado de tubo, canudo ou vermicello.

${ }^{11}$ Os exemplos citados são de Mariaelena Mondelli, 2001, p.198.
} 
Além de documentos literários, são inúmeros os documentos oficiais, citados por Mariaelena Mondelli (2001, p. 198) que atestam o aumento e a organização da produção, revenda e consumo de massas alimentícias em toda a península: em 7 de janeiro de 1316, o tabelião Giacomo Nepitello, de Gênova, registra um documento de locação da casa de Maria Borgogno, que, de profissão, facebat lasagnas; em 14 de janeiro de 1329, há o registro de um tal Gualterius Lasagnarius, morador de Prione (Gênova); em 1338, Mastro Barnaba, de Reatinis, em Reggio Emilia (Emília Romanha), escreve sobre os diversos nomes das massas alimentícias e observa que os vermicelli toscanos são conhecidos como orati em Bolonha, minutelli em Veneza, fermentini em Reggio e pancardelle em Mântua; em 1367, Donato Velluti, em sua Cronaca domestica, refere-se a uma mulher de origem siciliana, mas que vivia em Firenze onde administrava seu próprio negócio, "una fornaia, ovvero lasagnania" ("uma padeira, ou melhor, uma fazedora de lasanhas", tradução nossa).

No século XV, na Ligúria, aumenta a produção artesanal de fidei (fidéus), tipo de massa alimentícia, assim denominada no dialeto local. Em 1421, em Milão, torna-se necessário estabelecer um tabelamento de preços para as massas alimentícias (MONDELLI, 2001, p. 198). A necessidade de estabelecer-se essa medida e o fato de que, além de vendedores, havia também revendedores, indica que a indústria artesanal da fabricação de massas alimentícias era bastante profícua na época.

São desse século o Libro de arte coquinaria (1464-65 (?)) do Maestro Martino e o De honesta voluptate et valetudine (1445 (?)) de Bartolomeo Sacchi, o Platina.

No primeiro, encontramos diversas receitas regionais para o preparo de massas alimentícias, chamadas pelo autor maccaroni-maccaroni romaneschi, maccaroni in altro modo, maccaroni siciliani (maccheroni chi fir) -, e as primeiras indicações técnicas sobre a fabricação de vermicelli ${ }^{12}$ que, secos ao sol, podiam durar dois ou três anos. Na receita de maccaroni siciliani a palavra maccherone é encontrada, pela primeira vez, com o significado conhecido até nossos dias na maioria da península itálica, ou seja, um tipo de massa curta e furada. Os maccaroni romaneschi, segundo Capatti e Montanari, não são maccheroni no verdadeiro sentido da palavra, como descrito acima, mas tipos de massa alimentícia, conhecidos hoje em dia pelo nome de fettuccine e tagliatelle. Para Mondelli, maccaroni romaneschi são lasanhas e maccaroni in altro modo são tagliatelle (CAPATTI; MONTANARI, 1999, p. 62; MONDELLI, 2001, p. 198).

12 "Distempera la pasta [...] et filala sottile rompendola a pezoli peccini con le dita a modo di vermicelli,et poneli a secchare al sole." (Maestro Martino, Libro de arte coquinaria, p. 158 apud CAPATTI; Montanari, 1999, p. 62); 
O Platina retomará as mesmas receitas, substituindo, segundo Mondelli, o termo popular maccherone pelo termo mais erudito esicio. No décimo volume, é citado um tipo de massa recheada, que é o precursor dos raviólis. ${ }^{13}$

Capatti e Montanari observam que, apesar de reconhecermos nos documentos medievais e renascentistas os formatos de massas que usamos atualmente, os modos de preparo e os condimentos eram muito diferentes na época. O tempo de cozimento era muito mais longo e resultava em uma massa cuja qualidade al dente, tão apreciada pelos italianos de hoje, era inexistente. O queijo, condimento fundamental para a massa, podia ser adocicado com acréscimo de gordura animal (século XIV) ou manteiga (a partir do século XV) e especiarias doces, principalmente açúcar e canela. (CAPATTI; MONTANARI, 1999, p. 64).

No século XVI, Teófilo Folengo (1491-1544) inventa a poesia macarrônica escrita em uma língua em que se misturam palavras latinas com palavras italianas latinizadas. Segundo Mariaelena Mondelli (2001), o Olimpo das musas macarrônicas de Folengo é a terra de Bengodi, do Decamerão de Boccaccio, no qual, entre outras delícias, há maccheroni e lasagne, grandes nhoques feitos com farinha, queijo e manteiga, como, ainda hoje, são conhecidos os maccheroni no Vêneto. Em 1548, Giordano Bruno cita em Lo spaccio de la bestia trionfante a expressão napolitana "è cascato il maccarone dentro il formaggio" ("caiu o macarrão dentro do queijo", tradução nossa).

Documentos atestam que a produção e comercialização de massas alimentícias artesanais tornam-se atividades regulamentadas a partir dos séculos XVI e XVII. Os fabricantes passam a ter reconhecidos os estatutos de suas corporações em várias cidades da península.

Cristoforo di Messisburgo (1549) cita o uso da prensa (torchio) para a fabricação de massas alimentares e a importância de ter na despensa "maccheroni napoletani" e "vermicelli", demonstrando que a massa alimentícia seca podia ser estocada. Capatti e Montanari $(1999$, p. 66) afirmam que a massa era um produto caro e que, até a metade do século XVI, o preço dos maccheroni e das lasanhas, na Sicília, era três vezes mais caro do que o preço do pão. Documentos conservados no Arquivo Dória testemunham o uso de trefilas para a fabricação de massas em 1592 e informam que os fidelli, feitos a máquina, custavam menos do que os nhoques, feitos a mão. Em 1597, Oliviero Minuto obtém a licença para fabricar diversos tipos de massas alimentícias, isto é, "maccaroni, tagliatelle, formentini et simili", e para vendê-los no varejo. 0 documento registra que tal serviço asseguraria à população a possibilidade de adquirir seu sustento a um preço econômico (BARILLA, 2001, p. 19).

${ }^{13}$ MONDELLI, 2001, p. 198. 
Até esse século, os sicilianos, conhecidos pela alcunha de mangiamaccheroni (comedores de macarrão), exportavam massas alimentícias para Nápoles, cuja alimentação constituía-se principalmente de verduras (couve), pão e carne. $O$ epíteto de mangiafoglie (comedores de folhas) dado aos napolitanos atesta que as massas alimentícias em Nápoles eram um produto de luxo que, em tempos de carestia, deveria ser suprimido. $\mathrm{O}$ aumento demográfico e a crise na produção de carne aumentam o problema da escassez de alimentos. Contemporaneamente, a difusão da gramola e a invenção da prensa mecânica ${ }^{14}$ permitem a produção de massas alimentícias a um preço mais acessível. $\mathrm{O}$ binômio massa-queijo substitui o tradicional couve-carne. Segundo alguns estudiosos, essa solução evitou, em Nápoles, o dramático fenômeno da pelagra, uma doença causada pela falta de vitaminas decorrente de uma alimentação monófaga, centrada quase exclusivamente em polenta de milho (CAPATTI; MONTANARI, 1999, p. 57-58), uma vez que o queijo acrescenta as proteínas e gorduras que faltam aos cereais. No século XVII, a qualidade al dente passa a ser registrada como um dado importante na observação do tempo de cozimento da massa. As massas alimentícias são citadas como preparações culinárias adequadas para a época de abstinência de carne prescrita pela igreja (CAPATTI; MONTANARI, 1999, p. 64). À mesa dos nobres, no entanto, a carne continua sendo o prato principal, em particular a caça e as aves.

Multiplicam-se, a partir do século XVII, registros de documentos que tratam das massas alimentícias, seus tipos, formatos, ingredientes e denominações. Giovanni del Turco (1602) cita em seu Epulario nel quale si tratta del modo di cucinare carne, pescie, et ova receitas de massas frescas recheadas, seu modo de preparo, ingredientes e fases de confecção, como, por exemplo, os agnellotti in minestra (sopa de anhelotes), ou seja, "tortelli com recheio de carne, do tamanho de uma noz que devem ser envoltos em uma lâmina de massa, fina como a massa para lasanha, cortados com uma carretilha e, com os dedos, deve-se dobrar para cima toda a massa que tenha sobrado nos cantos" (MONDELLI, 2001, p. 200). Girolamo Aleandri (Veneza, 1630), em La difesa dell'Adone, revela que o termo fettuccia, na acepção de um formato de massa alimentícia, era usado como sinônimo de tagliatelli [com i], lasagnette e tagliolini (MONDELLI, 2001, p. 200).

o comércio de massas alimentícias é tão grande na época que o Papa Urbano VIII, em uma bula papal, impõe uma distância mínima de 24 metros entre as lojas que comercializam vermicelli (BARILLA, 2001, p. 14).

\footnotetext{
${ }^{14}$ Um documento emitido em Savona (Ligúria), em 1617, atesta que as massas alimentícias locais eram fabricadas a máquina (al tornio de fidelari), enquanto na Sardenha e na Sicília eram fabricadas a mão (BARILLA, 2001, p. 200). Segundo Marielena Mondelli (2001, p. 202), os dois maquinários já eram usados nas cortes e nas lojas dos fidelari desde o século XVI.
} 
No fim do século XVII, aparecem os primeiros registros do uso do tomate na forma de molho de tomate, principalmente em receitas de origem napolitana cuja influência ibérica é patente. É provável que o tomate já fosse usado pela população em geral antes de seu registro na cultura gastronômica da elite.

No século XVIII, os maccheroni passam a ser o emblema da Itália. $\mathrm{Na}$ Inglaterra, faz sucesso o Macaroni club onde se reúnem jovens viajantes apreciadores da boa mesa. Nos Estados Unidos, em 1789, Thomas Jefferson encomenda uma extrusora (torchio e trafila) para a fabricação de massas alimentícias. A sua disseminação no continente americano ocorrerá somente mais tarde, por obra dos imigrantes (MONDELLI, 2001, p. 201).

Em 1740, o genovês Paolo Adami obtém autorização para abrir em Veneza uma fábrica de massas finas "ad uso di Gênova", ${ }^{15}$ propondo-se ensinar seu preparo aos mestres e filhos de mestres dos pastifícios venezianos. Esse fato atesta haver uma diferença na preparação das massas nas duas cidades.

É publicado o tratado Delle specie diverse di frumento e di pane $e$ della panificazione (Florença, 1765), de Saverio Manetti, que descreve os diversos tipos de trigo para a fabricação das massas alimentícias e cita alguns formatos da época: vermicelli fini, maccheroni fini, tagliatelli sottili, foratini, semini.

Na nova Enciclopédie de M. Diderot e M. D’Alembert (1779), o verbete vermicelier descreve a pessoa que, por meio de um instrumento dotado de múltiplos furos, reduz a massa alimentícia a fios delgados com aparência de vermes e discorre sobre o modo como a massa é trabalhada e especifica dois tipos de prensa: a vertical, para as massas longas, e a horizontal, para as massas curtas, cortadas com uma lâmina fixa no centro da trefila (MONDELLI, 2001, p. 201).

Goethe, em Viaggio in Italia, define os maccheroni como uma massa delicada, feita com farinha fina, muito bem trabalhada, fervida e moldada em formatos peculiares.

Em fins do século XVIII, já havia o estereótipo de que os italianos comiam apenas macarrão (mangiamaccheroni). Conta-se que Carlo Goldoni, em uma viagem a Paris, quando convidado por uma senhora para o jantar, teria ouvido um dos convidados admoestá-la por ter servido sopa a um italiano, visto que os italianos comem só "macarrão, macarrão, macarrão".

Até 1833, a massa alimentícia em Nápoles era trabalhada com os pés. Ferdinando II de Bourbon encarregou o engenheiro Cesare Spadaccini de idealizar um sistema "mais higiênico" e, em 1834, é lançado um instrumento chamado homem de bronze para substituir o antigo processo.

${ }^{15}$ Até 1950 foram mantidas, para fins comerciais, as denominações "paste all'uso di Genova" e "paste di Napoli". 
É de 1819 o primeiro registro da palavra spaghetti com a acepção de massa alimentícia, no Dizionario della Lingua Italiana de Nicolò Tommaseo e Bernardo Bellini. ${ }^{16} \mathrm{Na}$ Cucina teorico-pratica (1839) de Ippolito Cavalcanti, duque de Buonvicino, temos o primeiro registro do uso do molho de tomate como condimento para a massa alimentícia e de seu preparo como é usado até hoje.

O estereótipo do napolitano devorador de macarrão converte-se em lugar comum. Capatti e Montanari (1999, p. 67) citam fontes históricas que atestam que, em 1860, época da unificação da Itália, quando Nápoles, capital do Reino, é anexada à Região do Piemonte por obra de Garibaldi, o conde de Cavour comenta em uma carta a Costantino Nigro: "i maccheroni son cotti e noi li mangeremo" "o macarrão está pronto e nós vamos comê-lo", tradução nossa). A referência gastronômica sugere, segundo alguns autores, que a unificação foi, em verdade, uma apropriação do Sul pelo Norte. ${ }^{17}$

A partir da segunda metade do século XIX, tem início a grande industrialização dos pastifícios em toda a costa napolitana, principalmente em Torre Anunziata que vive seus anos dourados de 1904 a 1914, quando toda a produção é vendida para o consumo interno e, principalmente, para o mercado externo. A revolução industrial na fabricação de massas alimentícias ocorre em outras cidades da península no mesmo período. Em 1877, em Parma, região da Emília Romanha, nasce a indústria de massas Barilla que, com uma pequena prensa de madeira, fabrica cerca de $50 \mathrm{~kg}$ de massa por dia. Em poucos anos, a produção atinge $200 \mathrm{~kg}$ por dia e, no início do século XX, $2.500 \mathrm{~kg}$. Em 1910, a nova instalação da fábrica produz oito toneladas/dia e, em 1940, a produção chega a 80 toneladas/dia de massas alimentícias. Gênova também desenvolve a automação no setor e, no final do século XIX, é, como Nápoles, um grande exportador de massas alimentícias. Em 1890, contavam-se 222 pastifícios apenas na província de Gênova e 148 nos arredores de Savona e de Porto Maurizio (hoje, província de Impéria), com uma produção de cerca de $400 \mathrm{~kg} /$ dia por fábrica. As massas de Gênova distinguiam-se das massas de Nápoles. Enquanto as primeiras eram comercializadas em forma de ninhos (matasse, novelos), as de Nápoles eram fios retos com uma curva em uma das extremidades, porque, quando saíam da prensa, eram pendurados em um bastão para secagem ${ }^{18}$ (BARILLA, 2001, p. 18).

16 "[...] Spaghetto, singolare maschile diminutivo di SPAGO. [...] Minestra di spaghetti: che sono paste della grossezza di un piccolo spago e lunghe, come i sopraccapellini." (MONDELLI, 2001, p. 202).

${ }^{17}$ La CECLA, F. La pasta e la pizza. Bologna: Il Mulino, 1998. p. 27-28, apud CAPATTI; MONTANARI, 1999, p. 67.

${ }^{18}$ Contam os autores que as pessoas do povo comiam as massas com as mãos. Suspendiam-nas com um garfo de madeira, pegavam alguns fios com a mão direita, elevando-os bem alto, e faziam chegar as extremidades à boca. (BARILLA, 2001, p. 18). 
O primeiro censo do setor, de 1937 , revela uma capacidade nacional produtiva de 1.250 .000 toneladas e uma produção efetiva de 600.000 toneladas (BARILLA, 2001, p. 27). As massas alimentícias eram, com efeito, o alimento típico italiano, confirmado pelo furioso ataque do futurista Marinetti: a abolição do macarrão, absurda religião gastronômica italiana.

A comparação do macarrão à religião revela que o preparo e o consumo das massas tinham, desde aquela época, seus próprios cânones e, como tais, deviam ser respeitados. A violação dos princípios dessa preparação representa para os italianos um crime punido não apenas pela degustação de um produto de qualidade inferior, mas, também, por lei. Em 1967, é promulgada a Lei n. 580, que regulamenta a produção das massas alimentícias italianas. A lei foi recentemente adequada ao Mercado Comum Europeu, mas manteve seus princípios fundamentais sobre as características que garantem a qualidade da massa alimentícia italiana.

\section{A cozinha italiana no Brasil}

Quando os imigrantes italianos chegaram ao Brasil, a partir de 1870, traziam com eles uma bagagem cultural maior do que o sonho de "Fazer a América”. Em São Paulo, da Hospedaria dos Imigrantes, muitos seguiram para as fazendas de café e outros se fixaram na cidade de maneira significativa desde o início. Ao se depararem com hábitos e culturas diferentes, eles viram na culinária uma maneira de preservação da identidade e transformaram irreversivelmente os hábitos alimentares do país. Não demorou muito para que o macarrão da mamma e a pizza, mesmo adaptados aos costumes e produtos locais, fossem incorporados ao cardápio do brasileiro e se transformassem nos principais símbolos da culinária italiana no Brasil. A falta de comprometimento com o rigor da tradição, nesse primeiro momento, deu origem a pratos como o capelete à romanesca (massa com molho de creme de leite, presunto cozido, cogumelos, ervilha e manteiga -, que não se encontra em Roma ou na Emília Romanha, por exemplo), o polpettone (grande almôndega de carne bovina, achatada, empanada, frita e servida com molho de tomate e queijo parmesão ralado - bem diferente da versão italiana, na forma de rocambole) e o filé à parmigiana (bife empanado e gratinado com molho de tomate e mussarela). Essas criações, embora nacionais, caracterizam e identificam a cozinha italiana em solo brasileiro, quer seja pelo uso de alguns ingredientes típicos ou pela referência a uma cidade italiana no nome. Ao lado delas, o fusilli à calabresa, a lasanha (normalmente feita com massa branca) e o cabrito assado compõem o cardápio da maioria das cantinas espalhadas Brasil afora. 
Em texto publicado na revista Veja São Paulo, no especial Comer $\&$ Beber 2001, definia-se os restaurantes italianos da seguinte forma:

Vem com força a cozinha de autor, com bons chefs italianos e alguns nacionais aculturados [...]. Nessa ascensão, fica faltando mais cozinha regional. A península itálica é uma colcha de retalhos de grandes sabores. Nós, aqui, vemos a coberta de uma cor só. É pena. Deve chegar o dia em que os pratos vão especificar a região de onde provêm ou de onde surge a inspiração para novas criações. ${ }^{19}$

Esse dia chegou. Com o novo tratamento destinado à gastronomia e a presença de chefs internacionais, os próprios restaurantes passaram a dar ao cardápio essa noção de origem, de regionalismo italiano. Não é mais um prato de massa e sim um reconhecimento e valorização das diferenças, com suas especificidades, o que se encontra em alguns restaurantes. Isto é, ao invés de um simples macarrão ao pesto, serve-se o trenette ao pesto genovese, típico da Ligúria, preparado com pinoli e o queijo pecorino ralado - sem adaptações como o uso de espaguete ou nozes.

De certo modo, estamos fazendo o caminho contrário: se no passado, absorveu-se uma cozinha italiana unificada onde não importava, para o brasileiro, se a lasanha era da Emília Romanha e a pizza da Campania, agora, demarca-se o território culinário. Ou seja, olha-se para a Itália com suas peculiaridades regionais de cultura e tipicidade. Fato que se reflete em restaurantes especializados em um determinado tipo de cozinha (toscana, napolitana, romana...), submetidos à supervisão de organizações como a Accademia Italiana della Cucina (que tem como objetivo a preservação da identidade dos pratos regionais) e em adequações de cardápios de casas já consagradas (como a Speranza, que trouxe um membro da Associazione Verace Pizza Napoletana para adequar três pizzas aos padrões da capital da Campania).

Esse movimento em prol da valorização da cozinha regional italiana motivou a Coleção Cozinhas da Itália, lançada entre 2011 e 2012, pelos jornais Folha de S. Paulo (São Paulo), Zero Hora (Porto Alegre), Pioneiro (Caxias do Sul) e $A$ Tribuna (Santos). Trata-se de uma seleção de 300 receitas, divididas em dezenove volumes, que abarcam uma amostra dos ingredientes típicos de cada uma das vinte regiões italianas, apresentando ao leitor a origem dos pratos e as diferenças entre o presunto San Daniele (produzido em Friuli-Venezia Giulia) e o de Parma (da Emilia Romagna), por em: 25/02/2013

${ }^{19}$ Disponível em: < http://veja.abril.com.br/especiais/comida/sp/italianos.html>. Acesso 
exemplo. Os livros também trazem características geográficas e culturais de cada trecho do país e pratos que atestam que a gastronomia italiana vai mundo além da pizza e da pasta.

\section{ConCLUSÃo}

A massa alimentícia é um produto emblemático da história da Itália. Sua origem remonta a épocas tão distantes que se confunde em histórias e lendas. A etimologia também é incerta. Percorre seu itinerário na bagagem (la pasta in valigia). Primeiro, na dos árabes do deserto que descobriram a técnica da secagem da massa para transportá-la. É essa característica essencial que favoreceu sua divulgação por todo o mundo. Da mesa dos pobres, foi nobilitada por condimentos e levada à mesa dos ricos. Volta à mesa dos pobres, após a invenção e difusão da gramola e do torchio mecânico que propiciaram produção a um preço mais acessível. Nos momentos de crise de produção de trigo, é eliminada da alimentação popular. Aceitou o acompanhamento do tomate, de origem americana, incorporando-o como ingrediente intrínseco em seus pratos. É, ao mesmo tempo, alimento requintado e popular. Esse paradoxo acompanha a massa alimentícia em sua viagem ao Brasil, que se torna cada vez mais presente nas mesas de todas as classes sociais. Seus ingredientes, aos poucos, se aprimoram. Chega o trigo duro, ingrediente do produto original, que, no natural processo de hibridação, característico da cultura gastronômica in valigia, havia sido substituído pelo trigo comum que era, se não o único, o mais acessível. Hoje, a Itália não é mais o país em que a pobreza e a fome expulsam seus habitantes, mas um país que exporta o Italian style e encontra em suas massas alimentícias um símbolo desse estilo. No Brasil, busca-se a verdadeira cucina italiana, procurando na cozinha de cada região o verdadeiro made in Italy.

\section{REFERÊNCIAS}

BACCIN, Paola. Terminologia alimentar italiana e a influenciada pelo italiano na cidade de São Paulo: um modelo de glossário. Tese (Doutorado em Língua e Filologia Brasileira) - Faculdade de Filosofia Letras e Ciências Humanas da USP, São Paulo, 2003.

BocCACCIO, Giovanni. Il Decameron. Firenze: Felice Le Monier, 1857.

BONI, Giovanni Battista Baldelli. Il milione di Marco Polo: testo di lingua del secolo decimoterzo ora per la prima volta pubblicato ed illustrato dal conte Gio. Batt. Baldelli Boni. Firenze: Torchi di Giuseppe Pagani, 1827. 
CAPATTI, Alberto; MONTANARI, Massimo. La Cucina Italiana: Storia di una cultura. Roma-Bari: Editori Laterza, 1999.

COLEÇÃo Cozinhas da Itália. São Paulo: Gold Editora Ltda., 2011/2012.

DEIANA, Roberta. Invito a cena con aforisma. 300 citazioni e "boutade" d'autore sul cibo. Torino: Il Leone Verde Edizioni, 2011.

GOTTI, Massimo Gotti. Grande enciclopedia illustrata della gatronomia. Milano: Selezione dal Reader's Digest, 2000.

GRIGUOL, Barbara (Org.). Le forme del gusto: la pasta, storia, tecnologia e segreti della tradizione italiana. Milano: Publicação de Barilla alimentare S.p.A., 2001.

HAZAN, Marcella. Fundamentos da cozinha italiana clássica. São Paulo: Martins Fontes, 1997.

LANDO, Ortensio. Commentario delle più notabili e mostruose cose d'Italia e altri luoghi di lingua aramea in italiana tradotto. Con un breve Catalogo de gli inventori delle cose che si mangiano e bevono, novamente ritrovato. Venezia: Bartholomeo Cefano, 1553.

MONDELLI, Mariaelena. Cronologia della pasta, di, liberamente tratto da Antico e vero come la pasta: Ricerca ragionata delle fonti storiche e documentali. In: GRIGUOL, Barbara (Org.). Le forme del gusto: la pasta, storia, tecnologia e segreti della tradizione italiana. Milano: Publicação de Barilla alimentare S.p.A., 2001. p.196-203.

VEJA SÃO PAULO. Comer \& Beber 2001-2002. São Paulo: Editora Abril, 2001. p. 55-56.

VITTORELLI, Jiacopo. Poesie. Pisa: Niccolò Capurro, 1809.

Submetido em: 03/11/2012

Aceito em: 13/02/2013 